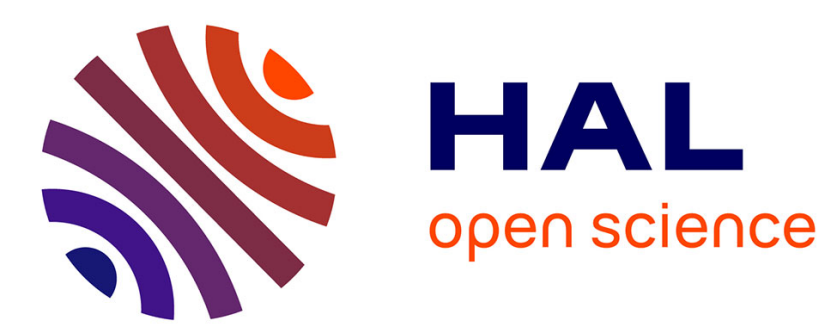

\title{
Plant colonization and survival along a hydrological gradient: demography and niche dynamics
}

Christian Damgaard, Amandine Merlin, Anne Bonis

\section{To cite this version:}

Christian Damgaard, Amandine Merlin, Anne Bonis. Plant colonization and survival along a hydrological gradient: demography and niche dynamics. Oecologia, 2017, 183 (1), pp.201-210. 10.1007/s00442016-3760-9 . hal-01475862

HAL Id: hal-01475862

\section{https://hal-univ-rennes1.archives-ouvertes.fr/hal-01475862}

Submitted on 24 Feb 2017

HAL is a multi-disciplinary open access archive for the deposit and dissemination of scientific research documents, whether they are published or not. The documents may come from teaching and research institutions in France or abroad, or from public or private research centers.
L'archive ouverte pluridisciplinaire HAL, est destinée au dépôt et à la diffusion de documents scientifiques de niveau recherche, publiés ou non, émanant des établissements d'enseignement et de recherche français ou étrangers, des laboratoires publics ou privés. 


\section{Plant colonization and survival along a hydrological gradient:}

\section{demography and niche dynamics}

Christian Damgaard ${ }^{1}$, Amandine Merlin $^{2,3}$, Anne Bonis $^{2}$

${ }^{1}$ Department of Bioscience, Aarhus University, Silkeborg, Denmark

${ }^{2}$ UMR 6553 ECOBIO: Ecosystems, Biodiversity, Evolution, CNRS-University of Rennes 1, OSUR, Rennes,

France

${ }^{3}$ Centre de recherche de la Tour du Valat, Arles, France

Author Contributions: $\mathrm{CD}, \mathrm{AM}$ and $\mathrm{AB}$ conceived and designed the investigations. $\mathrm{AM}$ measured plant abundance. $C D$ modelled the data. $C D$ and $A B$ wrote the manuscript. 


\section{Abstract}

2 Predicting the effect of a changing environment, e.g. caused by climate change, on realized niche dynamics

3 and, consequently, biodiversity is a challenging scientific question that needs to be addressed. One

4 promising approach is to use estimated demographic parameters for predicting plant abundance and

5 occurrence probabilities. Using longitudinal pin-point cover data sampled along a hydrological gradient in

6 the Marais poitevin grasslands, France, the effect of the gradient on the demographic probabilities of

7 colonization and survival was estimated. The estimated probabilities and calculated elasticities of survival

8 and colonization covaried with the observed cover of the different species along the hydrological gradient.

9 For example, the flooding tolerant grass $A$. stolonifera showed a positive response in both colonization and

10 survival to flooding, and the hydrological gradient is clearly the most likely explanation for the occurrence

11 pattern observed for $A$. stolonifera. The results suggest that knowledge on the processes of colonization

12 and survival of the individual species along the hydrological gradient is sufficient for at least a qualitative

13 understanding of species occurrences along the gradient. The results support the hypothesis that

14 colonization has a predominant role for determining the ecological success along the hydrological gradient

15 compared to survival. Importantly, the study suggests that it may be possible to predict the realized niche

16 of different species from demographic studies. This is encouraging for the important endeavor of predicting

17 realized niche dynamics.

19 Keywords: flooding gradient, niche dynamics, plant abundance, plant cover, plant demography 


\section{Introduction}

Different plant species are adapted to different water availability regimes, and competition from neighboring plants has been shown to control plant species occurrence and abundance (Araya et al. 2011; Grace and Wetzel 1981; Silvertown et al. 1999). In a demonstration of the effect of competition on species abundance along a hydrological gradient, Ellenberg (1952) sowed six meadow grass species in single species stands and in mixtures evenly across an experimental water table gradient. The experiment demonstrated that all species, when grown in monoculture, showed a peak in biomass production at an intermediate water-table depth, whereas when species competed with each other, the niche overlap was significantly reduced due to species segregating along the water table gradient (Silvertown et al. 1999). This difference between plant species occurrences in single species stands and mixtures of naturally found species along a hydrological gradient is an example of the difference between the fundamental and the realized niche, respectively (Hutchinson 1957).

The ecological success of plant species is typically described by the observed change in plant abundance. In order to more fully understand changes in plant abundance and make ecological predictions of the effects of environmental gradients, it is necessary to investigate and quantify the underlying ecological processes. In principle, this means that all the different interactions between the species in the plant community need to be investigated (Damgaard 2003), but this is typically an exceedingly demanding task in multi-species plant communities and, instead, we investigate how the vital rates of the most common species, when competing with other species, are affected by an environmental gradient (Harper 1977). The realized niche dynamics of a plant species along an environmental gradient are a function of both the environmental gradient and competitive effects of other species along the gradient. Predicting realized niche dynamics has been demonstrated to be useful in addressing both basic and applied ecological questions; e.g. for 
predicting species distribution with climatic change (Maiorano et al. 2013), for predicting species response to land use changes (Bomhard et al. 2005), and methodological issue for a better detection and sampling of rare populations (Guisan et al. 2006).

In this study, we assume that the vital rates measured in situ in natural plant communities along a gradient summarize the effect of both the gradient and interspecific interactions on the examined species, i.e. provide information on the dynamics of the species realized niche along the gradient. This connection between the Hutchinson realized niche and demography was first pointed out by Maguire (1973), who modeled niche space as functions of demographic parameters.

Generally, we expect that the local probability of occurrence is a function of the demographic parameters (Thuiller et al. 2014) and, more specifically, that it increases with the probability of colonization and decreases with the probability of mortality. Thuiller et al. (2014) analysed how demographic parameters relate to occurrence probability in trees and hypothesized that these relationships vary with competitive ability, but generally call for the need for empirical data that relate demographic parameters to occurrence probabilities. Furthermore, demographic processes have been increasingly used in spatio-temporal modeling of plant populations (Normand et al. 2014). This is motivated by the notion that changes in the probabilities of colonization and mortality may be the driving changes in species ranges. Furthermore, a demographic approach to understanding and predicting species' range dynamics has the advantage of being rooted in ecological theory (reviewed in Normand et al. 2014), and has been shown to improve predictive ability as it includes plasticity and local adaptation (Morin and Thuiller 2009).

Typically, colonization and survival probabilities are estimated from demographic data of individual plants. However, in many natural plant communities dominated by perennial plants, e.g. grasslands, it is often difficult to distinguish individual plants due to their vegetative growth pattern and, consequently, to obtain reliable demographic data. Instead, it is possible to measure "colonization" and "survival" by considering species turnover at a specific spatial point (Damgaard et al. 2011; Damgaard et al. 2013). If a species was 
present at time $t$ at a specific spatial point, but absent at time $t+1$, we may loosely speak of a mortality event, and if a species is absent from a specific pin-position at time $t$ and present at time $t+1$, we may loosely speak of a colonization event (Damgaard et al. 2011; Damgaard et al. 2013). We have chosen to use the term "colonization" rather than "recruitment", since the event is defined by a novel occurrence in space (Adler et al. 2006; Adler et al. 2009). However, in the interpretation of the results it is important to remember that the concepts of colonization and mortality have a different meaning than usual in demographic studies where individuals are clearly recognized. The used terminology is more accurate for some plant species than others; for perennial plant species that spread clonally by forming well-defined ramets, the concepts of colonization and mortality at a specific spatial point make apparent biological sense, whereas for species with more variable sizes, the concepts are inadequate descriptions of the underlying biological causes of a change in plant abundance. Bearing this issue of terminology in mind, we may generally assert that the cover of a plant species increases with colonization and decreases with mortality.

The aim of this study is to apply a demographic method that is suitable for multi-species communities, where it is not feasible to measure all interspecific interactions, in order to characterize the ecological processes that determine the width and segregation of the realized niches along a hydrological gradient. More specifically, we will measure the demographic processes, survival and colonization of naturally occurring perennial plant species along a hydrological gradient in Atlantic wet grasslands in France. The estimated demographic parameters will be compared to the observed probability of occurrence along the hydrological gradient, and the relative importance of survival and colonization in determining the occurrence probability along the hydrological gradient will be assessed and discussed. Finally, the application of the suggested method for estimating demographic parameters will be discussed and compared to the standard matrix demographic method. 


\section{Field site}

The study was conducted on grazed wet grasslands situated in the Marais poitevin on the French Atlantic coast $(46 \circ 28 \mathrm{~N} ; 1 \circ 13 \mathrm{~W})$. The climate is mild Atlantic with an average excess of precipitation over evapotranspiration in winter of $220 \mathrm{~mm}$ and a water deficit in summer of about 300-350 mm (Amiaud et al. 1998). The grasslands in the Marais poitevin are characterized by an elevation gradient with a range of $45 \mathrm{~cm}$ and a consequential flooding gradient varying in duration and water depth. Depending on the rainfall, the flooding starts in October and the grasslands generally start to dry out in June, although some years as early as in April (Amiaud et al. 1998).

The studied grasslands had a long term grazing history consisting of continuous grazing from the end of April to December with low stocking rate. This grazing disturbance and the consequent reduced importance of competitive interactions most likely act as filters on the regional species pool. In the studied plots, grazing was prevented during the two years the demographic study was carried out, but it was assessed that this period without grazing was too short to have caused significant changes in the plant community structure.

\section{Hydrological gradient and SEV}

Water is an essential and often limiting resource for plant growth, and insufficient water availability leads to decrease of transpiration and photosynthesis and, ultimately, to wilting and death. However, water may also be in excess, and waterlogging occurs when a large proportion of the pore spaces in the soil are occupied by water. This means the diffusion of oxygen and gas exchange between the soil, plants and atmosphere is limited. The result of this is decreased root growth and functioning, which negatively affects plant growth and survival (Araya and Garcia-Baquero 2014). 
In accordance with Gowing et al. (1998) and Stewtnam et al. (1998), we quantified the stress related to soil aeration-shortage and drought at each plot by the SEV method, which has been shown to quantify the trade-off between species' tolerance of aeration stress and tolerances of soil drying stress (Araya et al. 2011; Silvertown et al. 1999). The aeration shortage was measured by the Sum Exceedance Value above a reference threshold (aeration SEV) and the water shortage as the Sum Exceedance Value below a reference threshold (drought SEV), which depend on the physical properties of the soil (Gowing et al. 1998). A high aeration SEV indicates that plant roots are likely to be flooded and a high drought SEV indicates that plants will probably experience water-shortage. Both SEV parameters, expressed in $\mathrm{cm} \mathrm{day}^{-1}$, were derived from the water-table depth level monitored at hourly intervals from March to October using level logger sensors (Solinst LTC Levelogger Junior modell 3001). The aeration SEV was calculated as the cumulative difference between the water table depth and the reference level at which the plants were expected to be stressed by in the root zone at $100 \mathrm{~mm}$ depth (Gowing et al. 1998) and corresponds to a water table of $-0.42 \mathrm{~m}$.

The water level was found to be driven by elevation and, accordingly, both the aeration SEV and drought SEV correlated closely to the duration of flooding (Pearson correlation, $r=0.862, P<0.0001$ ). The aeration SEV was found to vary from 0.3 and $12.8 \mathrm{~cm} \mathrm{day}^{-1}$, a similar range as in British alluvial grasslands (Silvertown et al. 1999). The drought SEV varied between 28.3 and $45.4 \mathrm{~cm} \mathrm{day}^{-1}$, which is somewhat dryer conditions than in the British alluvial grasslands due to the very clay-rich soil and the relatively large rainfall

Since aeration SEV and drought SEV were highly correlated, the following demographic analysis was only performed for one of the two SEV measures, i.e. aeration SEV. 


\section{Plant species}

The vegetation at the site varies in composition along the hydrological gradient (Amiaud et al. 1998) and is dominated by grasses and sedges except after local heavy grazing episodes, where dicots may become transiently abundant (Marion et al. 2010). The flats, which are never flooded, present a mesophilous (M) plant community characterized by grasses and sedges such as Cynosurus cristatus, Lolium perenne, Elytrigia repens and Carex divisa. Flooding duration and water levels are variable on the intermediate slopes, from one to three months a year. The soil may be saline on the slopes and have salt-tolerant vegetation with a meso-hygrophilous (MH) plant community of sedges and grasses such as Juncus gerardi, Alopecurus bulbosus and Hordeum marinum. The depressions are flooded from winter to early spring, with a maximal water depth attaining $30-40 \mathrm{~cm}$. They have a hygrophilous $(\mathrm{H})$ plant community comprising flood-tolerant species such as Agrostis stolonifera, Glyceria fluitans and Eleocharis palustris.

In this analysis, we estimated the demographic parameters of six abundant perennial species with variable clonal growth forms (see Benot et al. 2009; Klimešová and Klimeš 2006) and in situ distribution along the elevation gradient. Agrostis stolonifera, which is a stoloniferous tussock forming species, is distributed all along the elevation gradient, but more frequent in flooded locations, Cynosurus cristatus and the stoloniferous Lolium perenne are tussock forming mesophilous species, and the tussock forming Hordeum secalinum occurs both in the mesophilous and meso-hygrophilous vegetation. Poa trivialis, which is a stoloniferous tussock forming species, is found in both the mesophilous and the hygrophilous vegetation, and the tussock forming Carex divisa is found all over the elevation gradient (Marion et al. 2010). For all the studied species, the fundamental niche and realized niche were previously found to be shaped by the aeration SEV or flooding duration (Merlin 2012; Violle et al. 2011). 


\section{Plant abundance measures}

\section{Demographic model} according to abundance. respectively.

Seventy permanent plots were placed along two elevation transects with a distance of $20 \mathrm{~cm}$ between plots. The cover of all the species in the plots was determined by the pin-point method: along both diagonals of the $25 \times 25 \mathrm{~cm}$ large plots, a pin was inserted every $4 \mathrm{~cm}$ for a total of 17 points per plot, and all the species that were touched by the pin were recorded. The abundance of the plant species was also measured by the vertical density, i.e. the number of times that a species touched each of the 17 pins in the pinpoint frame. The vertical density appeared to be integrative of the biomass growth of species during the growing season (Damgaard et al. 2009). The vertical density was used to order the different plant species

The abundance measurements were made on 23-29 October, 2008, 3-12 June, 2009, and 19-20 October, 2009. The main demographic analysis was made on the change in plant cover during an entire year, i.e. the pin-point data from October, 2008, was compared with the pin-point data from October, 2009. However, in order to study whether the importance of the demographic processes differed during winter flooding or during the spring-summer dry out period, we also compared the pin-point data from October, 2008, with the data from June, 2009, and the pin-point data from June, 2009, with the data from October, 2009,

Here, we consider absence-presence data of species $A$ from successive recordings from the same pin-point position. There are four possible transition events and corresponding probabilities between the successive recordings (Table 1). These transition probabilities depend on i) the probability ( $p$ ) that plant species $A$ is present at time $t$ (i.e. the cover of species A at time $t$ Damgaard 2009), ii) survival; the probability that plant species $A$ is present at the pin-point position both at time $t$ and time $t+1$, iii) colonization; the probability 

combined mortality and colonization is ignored.

The maximum likelihood estimates of the four parameters of colonization and survival (eqn. 1) were and their transition probabilities (Table 1 ) by maximizing the likelihood function of the multinomial distribution, and where the probability that species $A$ is present at time $t$ is estimated as, $p=\frac{X_{1}+X_{3}}{n}$, species $A$ is present at time $t$, 
If $\pi \leq \mathbf{1}$, then the probability of species $A$ being present, i.e. the cover of species $A$, decreases, and if

$201 \pi>1$, then the cover of species $A$ increases. The change in cover over time is a function of the colonization probability, the survival probability and the environmental gradient.

$\frac{c(z)}{\pi} \frac{\partial \pi}{\partial c(z)}=\frac{c-(p c(z) s(z))}{c+(p s(z))-(p c(z) s(z))}$

$$
\frac{s(z)}{\pi} \frac{\partial \pi}{\partial s(z)}=1-\frac{c(z)}{c+(p s(z))-(1-p)}
$$

Note than in the present application, where the species composition is allowed to vary along the hydrological gradient, the effect of the hydrological gradient on the demographic parameters cannot be separated from the possible changed competitive effect of the altered species composition.

\section{Estimation procedure}

The Bayesian joint posterior distribution of the four parameters of interest $\left(s_{\mathbf{0}}, s_{Z}, c_{\mathbf{a}}, c_{Z}\right)$ was estimated using a Bayesian MCMC algorithm (Metropolis-Hastings) for each of the species using likelihood function (2) and assuming that the prior distributions of the probabilities $c(z)$ and $s(z)$ were between zero and one. The MCMC iterations converged relatively quickly to a stable joint posterior distribution (results not shown), and the estimations were made from 100,000 iterations with a lag phase of 10,000 iterations. Judged from the plotted MCMC iterations, there was some covariance between the parameters that modelled the intercept and the slope in (1a) and (1b), respectively, but there was no covariance between the two parameters that modelled colonization (1a) and survival (1b), i.e. the effects of hydrology on colonization and survival was separated in the fitting procedure. The distribution of the elasticity of 
colonization and survival (4) was calculated from the joint posterior distribution of the parameters and the mean elasticity was normalized to one.

All calculations were done using Mathematica version 10 (Wolfram 2015).

\section{Results}

The marginal posterior distributions of the four parameters of interest $\left(s_{0,} s_{z}, c_{0}, c_{z}\right)$ are summarized in Table 2 for the six most abundant species. For $A$. stolonifera, which was the species with the highest abundance across the hydrological gradient, both the colonization and survival probabilities increased significantly with aeration SEV. For the three species that followed next in order of overall abundance, $C$. cristatus, L. perenne and $H$. secalinum, the colonization probabilities decreased significantly with increasing aeration SEV. For the two least abundant species, $C$. divisa and $P$. trivialis, the hydrological gradient was not found to have a significant effect on the colonization and survival probabilities. However, since the statistical power of the analysis is an increasing function of the number of discriminating demographic events, the latter negative results may be attributed to lack of statistical power.

The dependency of the colonization and survival probabilities with the hydrological gradient matched the occurrence pattern for the four most abundant species along the hydrological gradient, where $A$. stolonifera was the only species that increased in cover with increasing SEV (Fig. 1).

The relative sensitivity of the change in cover of the six most abundant species to the survival and colonization processes was determined by an elasticity analysis (Fig. 2). The elasticities are functions of the initial cover and the hydrological gradient (eqn. 4), and generally and as expected, the importance of the colonization process for a change in cover decreased with increasing initial cover. Furthermore, $A$. stolonifera differed qualitatively from the other species, i.e. the importance of colonization increased with aeration SEV for $A$. stolonifera, whereas the importance of colonization decreased with SEV for the other species. 
In order to study whether the importance of the demographic processes differed during winter flooding or within the spring-summer period, we also compared the pin-point data from October, 2008, with the data from June, 2009, and the pin-point data from June, 2009, with the data from October, 2009. The marginal posterior distributions of the four parameters of interest $\left(s_{0}, s_{n}, c_{0}, \varepsilon_{n}\right)$ for both winter flooding or within the spring-summer period were qualitatively similar to the posterior distributions reported for the whole year in Table 2, except that there was no significant effect of flooding on the colonization probability of $H$. secalinum (results not shown).

\section{Discussion}

\section{Effect of hydrological gradient}

In the Marais poitevin grasslands, it has previously been shown that the flooding pattern is related to occurrence probabilities, i.e. Violle et al. (2011) showed that the occurrence pattern of 27 out of 37 species responded significantly to the elevation (flooding) gradient. Here, we have estimated the demographic parameters of six of the most abundant perennial species and found that there was a consistent pattern between the estimated probabilities and calculated elasticities of survival and colonization as well as the observed cover of the different species along the hydrological gradient. The flooding tolerant grass $A$. stolonifera, which is most abundant when flooding is prolonged, showed a positive response in both colonization and survival to flooding and/or differing competitive effects of the changed species composition and differed qualitatively in all aspects from the other species. Accordingly, the hydrological gradient is clearly the most likely explanation for the occurrence pattern observed for $A$. stolonifera versus the other commonly observed species.

Demographic processes can be affected by hydrology and competition and, consequently, that hydrology affects the ecological success of different plant species along the hydrological gradient in wet fertile grasslands (Li et al. 2015; Lytle and Merritt 2004; Merlin et al. 2015; Scanga 2014). In a meta-analysis, 
Silvertown et al. (2015) showed that response to hydrological conditions is widespread (found in 43 out of 48 studies) and occur in a "remarkably wide range of terrestrial environments ranging from arid to wet". This suggests that the methods presented here generally may be used to predict the effect of a changing water regime in most grasslands communities or, possibly, the effect of other environmental drivers in grasslands communities (Harpole and Tilman 2006; Stevens et al. 2004).

\section{Predicting the realized niche}

Generally, we expect that the local probability of occurrence increases with the probability of colonization and decreases with the probability of mortality. In this study, we found that the dependency of the colonization and survival probabilities along the hydrological gradient matched the occurrence pattern for the four most abundant species along the hydrological gradient. This result indicates that knowledge of the processes of colonization and survival of the individual species along the hydrological gradient is sufficient for at least a qualitative understanding of species occurrences along the environmental gradient. Since it is the underlying assumption of this study that if the vital rates are measured in situ in natural plant communities along a gradient, then these vital rates will summarize the effect of both the environmental gradient and interspecific interactions on the examined species (Maguire 1973; Normand et al. 2014; Thuiller et al. 2014), we conclude that it may be possible to predict the realized niche along an environmental gradient from demographic studies. This is encouraging for the important endeavor of predicting realized niche dynamics in a changing climate (reviewed in Normand et al. 2014). The results are also in agreement with Adler et al. (2010), who found that demographic rates responding to niche dimension were rather stable and did not fluctuate across years.

In the study by Thuiller et al. (2014), the relationships between vital rates and occurrence probability were less clear than in our study, and they argue that this may be due to variable competitive effects. Indeed, the drawback of this and most other demographic studies is that the population ecological effect of variable abundance and interspecific competition is not taken into account as in a proper population ecological 
realistic empirical competition model of the effect of the environmental gradient on the plant community dynamics (Damgaard 2011; Merlin et al. 2015). However, demographic population models may be the best alternative to simple species distribution modelling in many multi-species plant communities where it is not feasible to measure all relevant plant-plant interactions (see also Wisz et al. 2013). It is, thus, interesting to assess the generality of the present finding, and we agree with Thuiller et al. (2014) that: "Despite the foundational nature of these ideas, quantitative assessments of the relationship between range-wide demographic performance and occurrence probability have not been made. This assessment is needed both to improve our conceptual understanding of species, niches and ranges and to develop reliable mechanistic models of species geographic distributions that incorporate demography and species interactions."

Furthermore, the results obtained are also ecologically meaningful due to explicit quantification of the niche dimension investigated, here flooding, as advocated by Smith et al. (2005) and suggested by Silvertown et al. (1999). The method also follows the suggestion of several authors to characterize the realized hydrological niche of each species and to build process-based models (e.g. Bartholomeus et al. 2011; Silvertown et al. 2015), which is motivated by the fact that a demographic approach of understanding and predicting species' range dynamics has the advantage of being rooted in ecological theory (reviewed in Normand et al. 2014). More specifically, the method allows an assessment of which suite of life history traits that affect either colonization or survival is most important for determining the width of the realized niche.

\section{Colonization vs. Survival}

The obtained results support the view that colonization has a predominant role for determining the ecological success along the hydrological gradient compared to survival. In the dense vegetation cover, where the importance of competition remains high throughout the flooding gradient, colonization ability appears to be the most important parameter for the ecological success of perennial plant (Li et al. 2015; 
Lytle and Merritt 2004; Merlin et al. 2015; Scanga 2014). These results are further corroborated by the finding of Chu and Adler (2015), who demonstrated the importance of the recruitment process for species niche space and fluctuation-independent coexistence for iteroparous herbs of open habitats. However, it is important to remember that the estimated colonization and survival probabilities as well as the connected elasticities are calculated from repeated pin-point cover data and, as mentioned before, the used terminology of colonization and survival is more accurate for some plant species than others.

More generally, the present findings suggest that the range of realized niches primarily is determined by the ability of a species to colonize new resource space in competition with other species rather than securing survival at an already colonized resource space. This finding is related to the seed limitation hypothesis, i.e. that many plant species are limited by colonization (Rees et al. 2001; Turnbull et al. 2000). Likewise, Adler et al. (2010) demonstrated that the recruitment process is more important than both survival and growth processes in determining niche differences. They hypothesized that pathogens and natural enemies have relatively strong effects during recruitment and mediate coexistence mainly at this stage of recruitment.

The importance of dispersal traits for the ecological success of plant species has previously been demonstrated by (e.g. de la Riva et al. 2011), and Schulze et al. (2012) showed that clonal growth is more important than sexual reproduction for determining population growth. In the Marais poitevin grasslands, the colonization process is dominated by clonal propagation; C. cristatus, L. perenne, H. secalinum and A. stolonifera provide numerous fast growing ramets (Benot et al. 2013), eventually supported by nutrients and carbohydrates provided from older better rooted ramets (Oborny et al. 2001). On the other hand, in 335 the absence of clonal vegetation growth/propagation, Jäkäläniemi et al. (2005) showed that survival had a 336 relatively large impact on patch dynamics. 


\section{Estimating demographic parameters}

338 In order to make general predictions from demographic studies, it is important that they are not

339 taxonomically biased; and this may be a problem in most traditional plant demographic studies, since

340 certain plant morphologies, such as clearly distinct individuals, flowers and seeds are more readily

341 measured and integrated into a matrix population model. For comparison, in the COMPADRE database of

342 matrix population models there are 316 records of Poaceae out of 6242 total plant records, which probably

343 is an underrepresentation of the family compared to its ecological role. In fact, one advantage of the used

344 demographic method of space occupancy is that it is not taxonomically biased, since all pin-point

345 measurements of the different species are performed at the same time.

\section{Acknowledgements}

347 We thank Marie-Lise Benot for help in the field and Olivier Jambon and Guillaume Bouger for water table monitoring. We are grateful to the Mairie des Magnils Reigniers for granting permission to work within its common and to the Parc Naturel Régional du Marais poitevin and the Etablissement Public du Marais poitevin for their support in maintaining the experimental setting where this survey was developed. 


\section{References}

Adler PB, Ellner SP, Levine JM (2010) Coexistence of perennial plants: an embarrassment of niches. Ecology Letters 13:1019-1029

Adler PB, HilleRisLambers J, Kyriakidis PC, Guan Q, Levine JM (2006) Climate variability has a stabilizing effect on the coexistence of prairie grasses. Proceedings of the National Academy of Sciences (USA) 103:12793-12798

Adler PB, HilleRisLambers J, Levine JM (2009) Weak effect of climate variability on coexistince in a sagebrush steppe community. Ecology 90:3303-3312

Amiaud B, Bouzillé J-B, Tournade F, Bonis A (1998) Spatial patterns of soil salinities in old embanked marshlands in western France. Wetlands 18:482-494

Araya YN, Garcia-Baquero G (2014) Ecology of water relations in plants. In: eLS. John Wiley \& Sons, Ltd Araya YN, Silvertown J, Gowing DJ, McConway KJ, Peter Linder H, Midgley G (2011) A fundamental, ecohydrological basis for niche segregation in plant communities. New Phytologist 189:253-258

Bartholomeus RP, Witte J-PM, van Bodegom PM, van Dam JC, Aerts R (2011) Climate change threatens endangered plant species by stronger and interacting water-related stresses. Journal of Geophysical Research: Biogeosciences 116:n/a-n/a

Benot M-L, Mony C, Lepš J, Penet L, Bonis A (2013) Are clonal traits and plastic response to defoliation good predictors of species resistance to grazing? Botany 91:62-68

Benot M-L et al. (2009) Responses of clonal architecture to experimental defoliation: a comparative study between ten grassland species. In: Valk AG (ed) Herbaceous Plant Ecology: Recent Advances in Plant Ecology. Springer Netherlands, Dordrecht, pp 257-266

Bomhard B et al. (2005) Potential impacts of future land use and climate change on the Red List status of the Proteaceae in the Cape Floristic Region, South Africa. Global Change Biology 11:1452-1468 
Chu C, Adler PB (2015) Large niche differences emerge at the recruitment stage to stabilize grassland coexistence. Ecological Monographs 85:373-392

Damgaard C (2003) Modelling plant competition along an environmental gradient. Ecological Modelling $170: 45-53$

Damgaard C (2009) On the distribution of plant abundance data. Ecological Informatics 4:76-82

Damgaard C (2011) Measuring competition in plant communities where it is difficult to distinguish individual plants. Computational Ecology and Software 1:125-137

Damgaard C, Merlin A, Mesléard F, Bonis A (2011) The demography of space occupancy: measuring plant colonisation and survival probabilities using repeated pin-point measurements. Methods in Ecology and Evolution 2:110-115

Damgaard C, Riis-Nielsen T, Schmidt IK (2009) Estimating plant competition coefficients and predicting community dynamics from non-destructive pin-point data: a case study with Calluna vulgaris and Deschampsia flexuosa. Plant Ecology 201:687-697

Damgaard C, Strandberg B, Mathiassen SK, Kudsk P (2013) The effect of nitrogen and glyphosate on survival and colonisation of perennial grass species in an agro-ecosystem: does the relative importance of survival decrease with competitive ability? PLoS One 8:e60992

de la Riva EG, Casado MA, Jiménez MD, Mola I, Costa-Tenorio M, Balaguer L (2011) Rates of local colonization and extinction reveal different plant community assembly mechanisms on road verges in central Spain. Journal of Vegetation Science 22:292-302

Ellenberg H (1952) Physiologisches und ökologisches Verhalten derselben Pflanzenarten. Berichte der Deutschen Botanischen Gesellschaft 65:350-361

Gowing DJG, Youngs EG, Gilbert JC, Spoor G (1998) Predicting the effect of change in water regime on plant communities. In: H. W, C. K (eds) Hydrology in a Changing Environment vol I. John Wiley, Chichester, pp 473-483 
Grace JB, Wetzel RG (1981) Habitat Partitioning and Competitive Displacement in Cattails (Typha): Experimental Field Studies. The American Naturalist 118:463-474

Guisan A et al. (2006) Using Niche-Based Models to Improve the Sampling of Rare Species

Utilización de Modelos Basados en Nichos para Mejorar el Muestreo de Especies Raras. Conservation Biology 20:501-511

Harper JL (1977) Population biology of plants. Academic Press, London

Harpole WS, Tilman D (2006) Non-neutral patterns of species abundance in grassland communities. Ecology Letters 9:15-23

Hutchinson GE (1957) Concluding remarks. Cold Spring Harb Symp Quant Biol 22:415-427

Jäkäläniemi A, Tuomi J, Siikamäki P, Kilpiä A (2005) Colonization-extinction and patch dynamics of the perennial riparian plant, Silene tatarica. Journal of Ecology 93:670-680

Klimešová J, Klimeš L (2006) CLO-PLA3-A database of clonal plants in central Europe. In, Institute of Botany, AS CR

Li S-L, Yu F-H, Werger MJA, Dong M, During HJ, Zuidema PA (2015) Mobile dune fixation by a fast-growing clonal plant: a full life-cycle analysis. Scientific Reports 5:8935

Lytle DA, Merritt DM (2004) HYDROLOGIC REGIMES AND RIPARIAN FORESTS: A STRUCTURED POPULATION MODEL FOR COTTONWOOD. Ecology 85:2493-2503

Maguire B, Jr. (1973) Niche Response Structure and the Analytical Potentials of Its Relationship to the Habitat. The American Naturalist 107:213-246

Maiorano L et al. (2013) Building the niche through time: using 13,000 years of data to predict the effects of climate change on three tree species in Europe. Global Ecology and Biogeography 22:302-317

Marion B, Bonis A, Bouzillé JB (2010) How much grazing-induced heterogeneity impact plant diversity and richness in wet grasslands ? Ecoscience 17:229-239 
Merlin A (2012) Importance des interactions biotiques et des contraintes environnementales dans la structuration des communautés végétales: le cas des marais atlantiques et des pelouses méditerranéennes. In. Université Rennes 1, p 280

Merlin A, Bonis A, Damgaard CF, Mesléard F (2015) Competition is a strong driving factor in wetlands, peaking during drying out periods. PLoS ONE 10:e0130152

Morin X, Thuiller W (2009) Comparing niche- and process-based models to reduce prediction uncertainty in species range shifts under climate change. Ecology 90:1301-1313

Normand S, Zimmermann NE, Schurr FM, Lischke H (2014) Demography as the basis for understanding and predicting range dynamics. Ecography 37:1149-1154

Oborny B, Czárán T, Kun Á (2001) Exploration and exploitation of resource patches by clonal growth: a spatial model on the effect of transport between modules. Ecological Modelling 141:151-169

Rees M, Condit R, Crawley M, Pacala S, Tilman D (2001) Long-term studies of vegetation dynamics. Science 293:650-655

Scanga S (2014) Population dynamics in canopy gaps: nonlinear response to variable light regimes by an understory plant. Plant Ecology 215:927-935

Schulze J, Rufener R, Erhardt A, Stoll P (2012) The relative importance of sexual and clonal reproduction for population growth in the perennial herb Fragaria vesca. Population Ecology 54:369-380

Silvertown J, Araya Y, Gowing D (2015) Hydrological niches in terrestrial plant communities: a review. Journal of Ecology 103:93-108

Silvertown J, Dodd ME, Gowing DJG, Mountford JO (1999) Hydrologically defined niches reveal a basis for species richness in plant communities. Nature 400:61-63

Smith M, Caswell H, Mettler-Cherry P (2005) STOCHASTIC FLOOD AND PRECIPITATION REGIMES AND THE POPULATION DYNAMICS OF A THREATENED FLOODPLAIN PLANT. Ecological Applications 15:10361052 
446 Stevens CJ, Dise NB, Mountford JO, Gowing DJ (2004) Impact of nitrogen deposition on the species richness of grasslands. Science 303:1876-1881

448 Stewtnam RD et al. (1998) Spatial relationships between site hydrology and the occurrence of grassland of conservation importance: a risk assessment with GIS. Journal of Environmental Management $54: 189-203$

451 Thuiller W et al. (2014) Does probability of occurrence relate to population dynamics? Ecography 37:11551166

Turnbull LA, Crawley MJ, Rees M (2000) Are plant populations seed-limited? A review of seed sowing experiments. Oikos 88:225-238

Violle C et al. (2011) Plant functional traits capture species richness variations along a flooding gradient. Oikos 120:389-398

Wisz MS et al. (2013) The role of biotic interactions in shaping distributions and realised assemblages of species: implications for species distribution modelling. Biological Reviews 88:15-30

Wolfram S (2015) Mathematica. In, 10.2 edn. Wolfram Research, Inc., Champaign, USA 
Table 1. The four possible events of two successive recordings of presence-absence data and their transition probabilities. $p=\frac{X_{1}+X_{3}}{n} ; s(z)=s_{0}+s_{z} z$ and $c(z)=c_{0}+c_{z} z$. The variables are explained in the text.

\begin{tabular}{|c|c|c|}
\hline Event & Description & Transition probability \\
\hline$X_{1}: A_{t}, A_{t+1}$ & $\begin{array}{l}\text { Species } A \text { was present in year } t \text { and was also present in } \\
\text { year } t+1\end{array}$ & $p(s(z)+c(z)(1-s(z)))$ \\
\hline$X_{2}: \operatorname{not} A_{t}, \operatorname{not} A_{t+1}$ & $\begin{array}{l}\text { Species } A \text { was not present in year } t \text { and was also not } \\
\text { present in year } t+1\end{array}$ & $(1-p)(1-c(z))$ \\
\hline$X_{3}: A_{t}, \operatorname{not} A_{t+1}$ & $\begin{array}{l}\text { Species } A \text { was present in year } t \text { but was not present in } \\
\text { year } t+1 \text { (indicates a possible mortality event) }\end{array}$ & $p(1-p)(1-c(z))$ \\
\hline$X_{4}: \operatorname{not} A_{t}, A_{t+1}$ & $\begin{array}{l}\text { Species } A \text { was not present in year } t \text { but was present in } \\
\text { year } t+1 \text { (indicates a possible event of colonization event) }\end{array}$ & $(1-p) c(z)$ \\
\hline
\end{tabular}


Table 2. Marginal posterior distributions (percentiles) of colonization and survival probabilities of the six most common species. $s(z)=s_{\mathrm{n}}+s_{z} Z$ and $c(z)=c_{0}+c_{\square} z$. The probability that the effect of the hydrological gradient on $s_{\square}$ or $\varepsilon_{\square}$, is greater than zero is also shown (note that significant departures from zero includes both $\mathrm{P}(>0)<0.05$ and $\mathrm{P}(>0)>0.95)$. The species are ordered in decreasing abundance across the hydrological gradient. The variables are explained in the text.

\begin{tabular}{|c|c|c|c|c|c|c|c|c|c|c|c|c|c|c|}
\hline \multirow[t]{2}{*}{ Species } & \multicolumn{3}{|c|}{$s_{0}$} & \multicolumn{4}{|c|}{$s_{I I I}$} & \multicolumn{3}{|c|}{$c_{0}$} & \multicolumn{4}{|c|}{$c_{I}$} \\
\hline & $2.5 \%$ & $50 \%$ & $97.5 \%$ & $2.5 \%$ & $50 \%$ & $97.5 \%$ & $P(>0)$ & $2.5 \%$ & $50 \%$ & $97.5 \%$ & $2.5 \%$ & $50 \%$ & $97.5 \%$ & $P(>0)$ \\
\hline Agrostis stolonifera & 0.333 & 0.473 & 0.604 & -0.002 & 0.022 & 0.039 & 0.965 & 0.394 & 0.455 & 0.510 & 0.021 & 0.033 & 0.040 & 1.000 \\
\hline Cynosurus cristatus & 0.042 & 0.117 & 0.192 & -0.011 & -0.001 & 0.020 & 0.425 & 0.072 & 0.112 & 0.161 & -0.010 & -0.006 & 0.001 & 0.033 \\
\hline Lolium perenne & 0.048 & 0.238 & 0.457 & -0.029 & -0.009 & 0.019 & 0.232 & 0.226 & 0.278 & 0.336 & -0.022 & -0.018 & -0.012 & 0.000 \\
\hline Hordeum secalinum & 0.004 & 0.114 & 0.455 & -0.017 & 0.007 & 0.052 & 0.728 & 0.167 & 0.247 & 0.346 & -0.022 & -0.014 & -0.002 & 0.014 \\
\hline Carex divisa & 0.004 & 0.086 & 0.284 & -0.008 & 0.024 & 0.054 & 0.921 & 0.063 & 0.108 & 0.168 & -0.006 & 0.002 & 0.012 & 0.681 \\
\hline Poa trivialis & 0.003 & 0.066 & 0.365 & -0.019 & 0.012 & 0.056 & 0.766 & 0.112 & 0.194 & 0.308 & -0.019 & -0.008 & 0.010 & 0.172 \\
\hline
\end{tabular}


2 Fig. 1. The cover of the six most common species along the hydrological gradient (aeration SEV) is shown

3 for the first year ( $1=100 \%$ cover). The fitted line is the model (constant, exponential, or sigmoid) that was

4 best supported by the pin-point cover data (lowest AIC). The best fitting models were a) A. stolonifera:

5 exponential; b) C. cristatus: sigmoid; c) L. perenne: exponential; d) H. secalinum: constant; e) C. divisa:

6 sigmoid; f) P. trivialis: exponential

7 Fig. 2. Elasticity of survival and colonization of the six most common species at varying initial cover (solid

8 blue: $p=0.01$, dotted black: $p=0.1$, dashed green: $p=0.5$, dotted-dashed red: $p=0.9$. Note that

9 the two elasticities sum to one. If the lines increase (decrease) with aeration SEV then the relative

10 importance of survival increases (decreases) with aeration SEV. Color version of this figure is available

11 online. 
Fig. 1
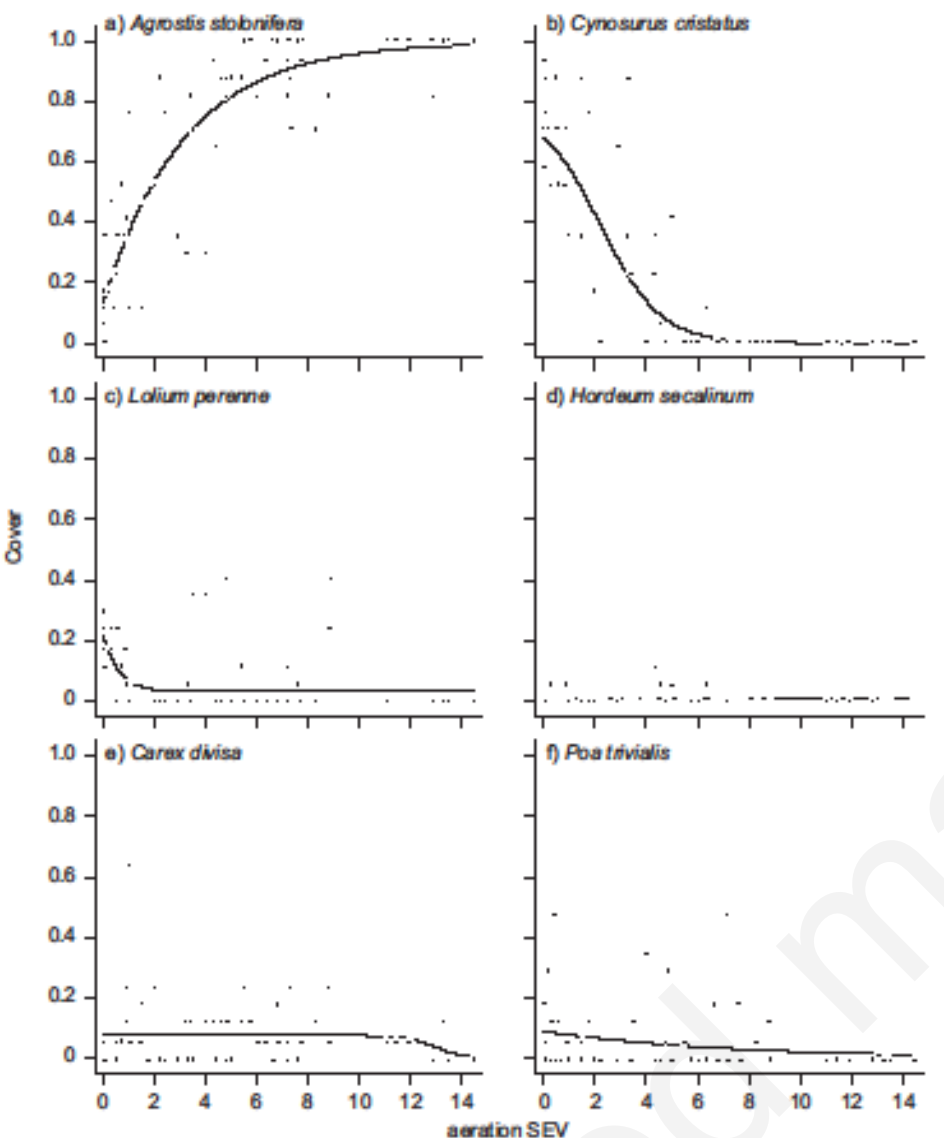
Fig. 2
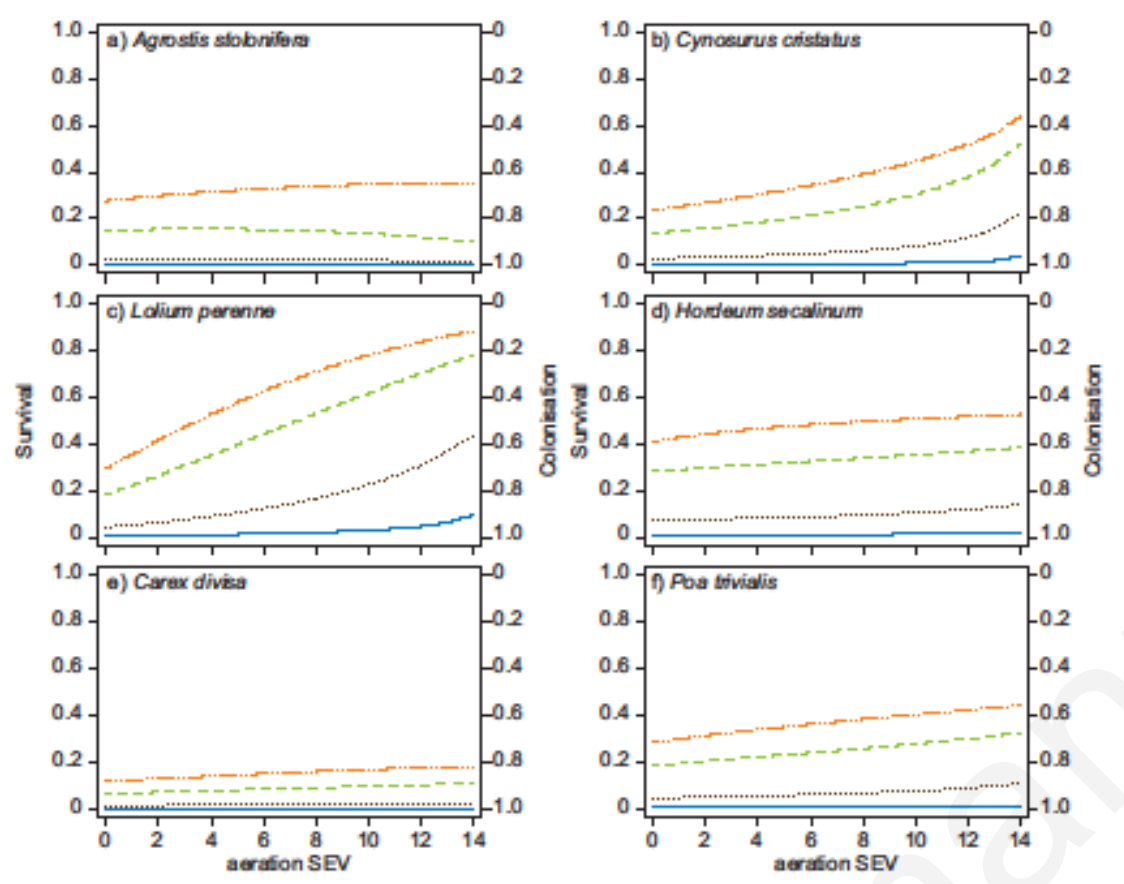